\title{
KANT Y LA DIFERENCIA SEXUAL
}

\section{KANT AND SEXUAL DIFFERENCE}

\author{
LuISA POSADA KuBISSA* \\ Universidad Complutense de Madrid
}

Resumen: Este artículo se hace cargo de un aspecto del pensamiento kantiano poco conocido, como es su filosofía sobre los sexos. Este aspecto, que compone lo menos ilustre del filósofo ilustrado, se aborda en particular a partir de la hermenéutica feminista contemporánea y, más concretamente, de la que procede de la órbita alemana. A partir de aquí se concluye cómo esta filosofía de los sexos de Kant se sitúa en posiciones no alejadas del esencialismo del pensamiento de la diferencia sexual, tal como el mismo se expresa en sus pensadoras fundacionales, como es el caso de la francesa Luce Irigaray.

Palabras Clave: Feminismo filosófico, Ilustración, diferencia sexual, esencialismo

Авsтract: This article takes up a less well-known aspect of Kantian thought, his philosophy of the sexes. This aspect, the least illustrious one of this Enlightenment philosopher, is dealt with in particular based on contemporary feminist hermeneutics, and, more specifically, based on German contemporary feminist hermeneutics. From this point, I conclude that Kant's philosophy of the sexes is situated in positions not far from the essentialism of thinking regarding sexual difference, as expressed in founding thinkers, such as the French thinker Luce Irigaray.

* Profesora Titular del Departamento de Teoría del Conocimiento, Estética e Historia del Pensamiento Facultad de Filosofía- Universidad Complutense de Madrid

Ciudad Universitaria s/n-28040-Madrid

lposada@filos.ucm.es 
Keywords: Philosophical feminism, Enlightenment, sexual difference, essentialism

\section{Sobre la filosofía de los sexos kantiana}

Sin duda, establecer como estación hermenéutica la revisión del pensamiento kantiano desde el feminismo filosófico ${ }^{1}$ resultará todavía hoy para muchos algo casi irreverente. E incluso nuestro filósofo podría cuestionar la pertinencia de incluir tal recorrido en la cartografía del viaje por la razón pura. Pero se trata de adentrarse en esos derroteros del pensamiento de Kant como tarea inexcusable a la hora de dar cuenta de aquellos aspectos de su pensamiento que han quedado más en la sombra.

El contexto de la filosofía kantiana responde a las mismas claves en las que cabe cifrar el pensamiento ilustrado cuando de la consideración de las relaciones entre los sexos se trata. Aquí Kant se olvida de su consigna ilustrada de ;Sapere aude! y considera sin ningún reparo que «Una mujer letrada (...) tendría además que tener barba» (Kant, 1977 a, 852), cosa que, más allá de una anécdota de mayor o menor enjundia, constituye la expresión de un pensamiento común por la época. Pero, como hemos tenido ocasión de subrayarlo ya en otro trabajo (Posada Kubissa, 2008) a la hermenéutica feminista sí le ha de importar, y mucho, desvelar esta zona oscura del gran pensador de las Luces -que viene a coincidir en ello, dicho sea de paso, con casi toda la tradición predominante en la historia del pensamiento pre- y postilustrado-. Y con ello el feminismo filosófico se convierte en critica de la crítica: en una revisión de la filosofía ilustrada que, sin pretender invalidarla, sí quiere denotar sus insuficiencias, radicalizando su propio discurso igualitario y universalizante, hasta hacerlo extensivo a todo el

1 Utilizamos aquí la expresión feminismo filosófico retomándola del significado que la misma tiene en Celia Amorós, quien lo entiende del siguiente modo: «He de aclarar, por otra parte, que prefiero con mucho hablar de feminismo filosófico que de filosofía feminista. A la filosofía 'qua tale' quizás no sea pertinente adjetivarla. Por otra parte, si distinguimos entre tareas deconstructivas y reconstructivas de la filosofía, quienes a estos menesteres nos dedicamos hemos de confesar que, hoy por hoy, son las primeras las que prioritariamente nos ocupan. Tras siglos de filosofía patriarcal, hecha fundamentalmente -si bien con más excepciones de lo que a primera vista parece- por varones y para varones, la tarea de deconstrucción - no en su sentido técnico derrideano sino en un sentido más amplio en el que se utiliza como sinónimo de crítica- es todavía ingente. (..) Prefiero, por estas razones teóricas y algunas otras de orden pragmático, hablar más bien de feminismo filosófico (...). Pues lo que se quiere dar a entender con esta denominación es que el feminismo es susceptible de ser tematizado filosóficamente» (Amorós, 2000, 9-10). 
conjunto de las mujeres, más allá por tanto de los límites en los que fue pensado (Posada Kubissa, 2008, 269).

No entraremos aquí a reconsiderar un periodo tan conocido y estudiado como es el periodo ilustrado. Pero sí diremos que, a grandes rasgos, hubo una Ilustración emanada y resuelta para la parte masculina de la humanidad, pero que también fue este mismo fenómeno ilustrado la génesis del feminismo, como movimiento teórico y político articulado en torno a la reclamación de la igualdad entre los sexos. A esta otra tradición ilustrada es a la que mira el feminismo filosófico, para reconocer en ella un discurso de la vindicación en figuras como la de la revolucionaria francesa Olimpia de Gouges, la radical inglesa Mary Wollstonecraft, o mucho antes, en 1763, la del filósofo cartesiano Poullain de la Barre y su disertación Sobre la igualdad de los dos sexos.

Volviendo al caso de Kant, hay que decir que entre 1764 y 1798 este filósofo mantuvo y reafirmó posiciones idénticas en lo que se refiere a la antropología de los sexos y a su concepción del ser femenino. Y también cabe subrayar, antes que nada, que las tesis kantianas en lo que hace a los sexos no son ni mucho menos originales. En ellas se aprecia explícitamente - como en otros aspectos- la influencia del discurso de Rousseau, cuya honda radicalidad en la reclamación de igualdad para el ámbito de la ciudadanía pública va de la mano de una profunda concepción de la desigualdad en lo tocante a la relación entre el Emilio rousseauniano y su compañera Sofía en el terreno discursivo que se refiere al ámbito de lo privado-doméstico (Pateman, 1995), (Armstrong, 1991), (Cobo, 1996).

En Rousseau cristaliza el discurso de la feminidad normativa propio de la modernidad, en particular cuando en 1762 hace pública su concepción de la pedagogía femenina en el capítulo V de su Emilio o de la educación. En estas elaboraciones, Rousseau proyecta y conceptualiza la transformación que la moderna sociedad supuso en el ámbito de la familia entre los siglos XVI y XVIII (Flandrin, 1977), y cómo tal transformación vino a generar un doble discurso en el imaginario de los filósofos ilustrados: aquél que se refiere a la acérrima defensa del orden igualitario en el terreno de lo público, y el que defiende los valores propios de una burguesía naciente, no tan igualitarios, para el ámbito de la vida familiar y privada (Beaujean, 1977).

En el discurso de Kant sobre los sexos encontramos también ese doble discurso, que hace punto y aparte de las consignas emancipatorias ilustradas cuando se aplica a las cuestiones propias del mundo doméstico. Como ha resaltado la crítica 
feminista de origen germano, la filosofía de los sexos de Kant es menos moderna que la de Rousseau, ya que en ella se percibe el cruce entre los planteamientos afines a la modernidad, por un lado, y las viejas concepciones de la relación entre los sexos, por otro (Duden, 1977, 125-140), (Nolte, 1963, 346-362). En este sentido hay que destacar que Kant parece participar en efecto del modelo moderno-burgués de pensamiento cuando entiende el matrimonio en términos contractuales, como un pacto que se sella con el fundamento del amor recíproco. Sin embargo, a la vez parece mantenerse en una concepción premoderna del matrimonio, cuando piensa el contenido de este pacto como la necesidad de pacificación de la sempiterna guerra entre los sexos.

Sea como fuere, el resultado de esa unión entre los sexos para Kant, como lo declara, es « la pareja unida que configura una sola persona moral» (Kant, 1977a, 867). Esta idea de las Beobachtungen über das Gefühl des Schönen und Erhabenen (Observaciones sobre el sentimiento de lo bueno y lo sublime) reaparece más de treinta años después (en su Anthropologie in pragmatischer Hinsicht - Antropología desde el punto de vista pragmático-), cuando declara que el terreno donde se puede encontrar la unidad entre la diversidad de los sexos es el matrimonio, en el que la fórmula de gobierno se divide entre la mujer que "manda» y el hombre que «reina» (Kant, 1977b, 657): «Para la unidad e indisolubilidad de una unión es insuficiente el encuentro cualquiera de dos personas; una parte tiene que someterse a la otra y recíprocamente una parte tiene que situarse por encima de la otra para poder dominarla o gobernarla» (Kant, 1977b, 648).

Kant advierte en sus Observaciones que esa persona moral, que surge de la unión civil de un sexo con el otro, puede romperse si ambos extremos no preservan sus diferencias, impuestas a cada uno por ley de la naturaleza misma (Kant, 1977a, 868). Por esta ley cada sexo experimenta por el otro el fortalecimiento de su diferencia; y así la desigualdad natural encuentra lugar en el terreno éticosocial (Kersting, 2012).

Desde la hermenéutica feminista alemana ha habido quien ha querido releer esta posición kantiana en clave positiva. Así, la filósofa Ursula Pia Jauch, por ejemplo, se congratula de que este filósofo aporte un proyecto de perfectibilidad moral de la humanidad toda, donde cabría incluir una potencial y futura mejora de la condición misma de las mujeres. Esta interpretación viene a resumirla la teórica alemana apuntando que en la antropología kantiana «El hombre es, la mujer debe llegar a ser» («Der Man ist, die Frau soll werden»), lo que no sería 
otra cosa que una llamada, ciertamente ilustrada, a un futuro de igualdad entre los dos sexos (Jauch, 1988, 44).

Frente a este optimismo hermenéutico de Jauch, otras pensadoras alemanas han remarcado que el discurso kantiano sobre los sexos no es otra cosa que la expresión de la voluntad masculina de pensar a las mujeres «como un objeto de la razón práctica de los hombres» en términos de la filósofa Lieselotte Steinbrügge $(1989,65)$. E, incluso, también encontramos una lectura de los intereses de la antropología kantiana diametralmente opuesta a la ya mencionada de Jauch: en efecto, cabe interpretar para algunas estudiosas feministas que en este pensador se da el «contrapunto a la concepción unitaria de la humanidad que tuvo el racionalismo", y que, por tanto, con Kant "pasamos ahora a una diversidad insalvable entre los sexos", como lo sostiene Heidemarie Bennent-Vahle ( 1991 32-33).

Esta diversidad insalvable, que conlleva un esencialismo sobre los sexos, se traduce en una pedagogía diferenciada para el sexo femenino, por la que ya en sus Observaciones de 1764 Kant apuesta por que

(La mujer) no aprenderá, por tanto, geometría; acerca del principio de razón suficiente o de las mónadas ha de saber sólo lo imprescindible (...). Las bellas pueden dejar a Cartesius girando en su torbellino, sin inmutarse aun cuando Fontenelle quiera acompañarlas bajo las estrellas; y su atractivo nada pierde en fuerza porque ignoren lo que Algerotti se esforzó por describir acerca de las fuerzas de atracción de la materia siguiendo a Newton. En cuanto a la historia, no se llenarán la cabeza con batallas; y en lo referente a la geografía tampoco lo harán con nombres de fortalezas, porque es tan impropio de ellas oler a pólvora, como lo es de los hombres el oler a almizcle" (Kant, 1977 a, 852-853).

Si el relato rousseauniano acerca de la salida del ser humano del estado de naturaleza y su posterior paso civilizatorio se desentiende de explicar por qué cuando aparece el contrato social las mujeres ya están excluidas del mismo, el imaginario kantiano reincide en su Antropología en la sujeción femenina por razón del orden natural de las cosas, un orden que fundamenta el sometimiento también natural de la mujer al varón: en el estado de naturaleza, afirma Kant en su Antropología, «la mujer es un animal doméstico. El hombre camina por delante con las armas en la mano, y la mujer le sigue con la carga de los enseres de la casa» (Kant, 1977 b, 649). Por cierto que Kant reiterará en Die Metaphysik der 
Sitten, al ocuparse del derecho conyugal, la idea de la "superioridad natural" de la capacidad masculina sobre la femenina (Moser, 2001). Y lo hará en un amplio pasaje que se enuncia como sigue:

Si la cuestión consiste en saber si también se opone a la igualdad de los casados como tales que la ley diga del varón en relación con la mujer: él debe ser tu señor ( él la parte que manda, ella la que obedece), no puede pensarse que esta ley está en conflicto con la igualdad natural de una pareja humana, si a la base de esta dominación se encuentra sólo la superioridad natural de la capacidad del varón sobre la mujer a la hora de llevar a cabo el interés común de la casa y el derecho al mando, fundado en ella; cosa que puede derivarse, por tanto, incluso del deber de la unidad y la igualdad con vistas al fin (Kant, 1977c, 392).

En Kant - dado que la relación conyugal se produce como contrato que necesariamente ha de establecerse para acabar con la natural guerra de los sexosel contrato sexual surge como necesidad natural. Y esto equivale a decir que responde al mismo orden natural en el que se inscribe la guerra entre los sexos, de modo que, sin explicitarlo, Kant está concediendo que hay un contrato sexual que precede y posibilita el contrato social. Pero, si esto es así, cabe decir que ese contrato sexual originario, más que contrato, es una capitulación: al formar parte de la necesidad, y por tanto del orden natural de las cosas, se trata de un sometimiento no pactado, de un contrato sexual que se realiza en términos de sujeción del sexo femenino por el masculino (Pateman, 1995).

De lo anterior se desprende que la filosofía de los sexos de Kant puede ser comprendida como una filosofía pre-contractual y, con ello, pre-moderna, pues en ella el contrato no existe, ni es, por tanto, el fundamento último al que remitir el orden socio-sexual. Desechado el amor como sello moderno del pacto de matrimonio, sólo cabe comprender la relación conyugal como un equilibrio en la guerra entre los sexos: un juego natural de poder, que se expresa en términos particularmente explícitos cuando Kant afirma, por ejemplo que «La mujer rehúsa, el hombre pretende; el sometimiento de aquella es favor que se le hace» ( Kant, 1977b, 652).

A partir de este naturalismo kantiano sobre la relación entre los sexos cabría apuntar que su discurso resulta ser menos peligroso para las reclamaciones igualitarias que, por ejemplo, el discurso rousseauniano. Porque su arbitraria defensa del sometimiento como estado natural de la mujer y su conceptualización 
de la dinámica entre los sexos como un perpetuo enfrentamiento no oculta las premisas desigualitarias de las que parte, ni pretende hacer pasar tal estado de cosas por la ley natural del amor.

Por ello hay alguna pensadora feminista, como Ursula Pia Jauch, a quien ya hemos nombrado, que discute las interpretaciones de la filosofía de los sexos de Kant como un paradigma del discurso patriarcal: muy por el contrario, a Jauch le preocupa que la crítica feminista cargue demasiado las tintas sobre el filósofo prusiano y que, con ello, se corra el riesgo de deconstruir el pensamiento kantiano con la consiguiente pérdida irreparable de las virtualidades que este potente discurso crítico-ilustrado tiene. En este sentido Jauch lamenta la mala y escasa interpretación que se ha hecho de las Beobachtungen (las Observaciones) en lo que se refiere a la caracterización kantiana de los sexos. Y de ahí provendrían, a juicio de esta filósofa, lecturas feministas erróneas, que quieren hacer de este texto una especie de declaración programática del pensamiento patriarcalista.

También ha habido defensas recientes de las virtualidades emancipatorias del pensamiento moral kantiano, que han argumentado que "ya que el sexismo de Kant en sí mismo no infecta la totalidad de la teoría moral, esta teoría permanece como algo que las feministas no deberían ignorar» (Hay, 2013, 61). Pero una buena parte de la crítica feminista no ha sido precisamente benevolente con las consideraciones kantianas en lo que hace a sus observaciones antropológicas sobre la diferencia sexual. Así, por ejemplo, Silvia Bovenschen afirma tajantemente que las mujeres en Kant no son culpables de ser menores de edad. Pero que no lo son porque, al no ser las mujeres susceptibles del estatus de sujeto, no pueden ser consideradas ni siquiera culpables de su propia situación de eterna infancia (Bovenschen, 1979, 135).

También hay investigaciones feministas, como la de Bennent- Vahle, que entienden que Kant participa de la ficción pre-romántica de la unidad originaria entre lo bello y lo bueno, por cuanto habla del «entendimiento bello» del ser femenino, que a su juicio cristaliza el «espejo de los sueños masculinos de armonía»: así las mujeres se orientarían moralmente a rechazar el mal, no porque sea malo, sino porque es feo (Bennent-Vahle, 1985, 103). Pero también hay que recordar que ha habido interpretaciones en la órbita germana, que han considerado sin paliativos que las observaciones kantianas sobre los sexos son, pura y llanamente, misóginas, como lo considera el estudio pionero de Buytendijk $(1953,64)$. 
De nuevo traemos a colación a Jauch, quien discute estas interpretaciones que considera desacertadas de las tesis de Kant sobre los sexos. Y razona en los siguientes términos:

Hay que aclarar, antes que nada, si las observaciones de Kant sobre la "relación de los sexos"- como titula la tercera y última parte de sus Observaciones dedicada a la diferencia sexual- pueden entenderse sin más como intento paradigmático de legitimación del ideal burgués de feminidad (Jauch, 1988, 63).

A la hora de "aclarar" esta cuestión, la filósofa feminista concluye que esto es a la vez verdadero y falso: es verdadero, si consideramos el diseño de la feminidad en las Observaciones desde el modelo burgués que manifiestan en su superficie; pero no lo es, si tomamos en cuenta que «Kant está en disposición ahí de analizar el concepto burgués de mujer como artefacto o constructo, desprovisto de subjetividad» (Jauch, 1995, 103).

Por otra parte, no parece errático interpretar que en Kant la mujer no es otra cosa que un varón defectivo, que no tiene en sí el fundamento para su perfectibilidad, como sí lo tiene en cambio el sexo masculino. Pero esa defectividad femenina convoca inmediatamente una suerte de discurso de la excelencia, por el cual Kant viene a establecer que el "entendimiento bello» del ser femenino es necesario para que pueda pensarse siquiera la unidad originaria entre sensibilidad y entendimiento. Se trata de un pensamiento de la complementariedad que apunta a la unidad entre el gusto de la mujer y el intelecto del varón, cosa que viene a expresar una de las ideas propia del discurso de los filósofos de la modernidad ilustrada (Konnertz, 1991, 103).

Las Observaciones alcanzaron en vida de Kant un total de ocho ediciones y constituyeron, con ello, uno de sus escritos más populares. Las noticias de la época dan cuenta de que la recepción de este escrito tuvo gran repercusión entre el público femenino, de modo que puede decirse que formó parte de esa "filosofía de damas", que Jauch defiende que se dio entre los siglos XVII y XVIII como una batalla dentro de la más amplia guerra contra la filosofía de las escuelas (Jauch, 1995). Pero, aun así no parece justificado entender que la orientación popular, casi de escrito a la moda de esas Observaciones kantianas altere sustancialmente lo que en ellas se dice, ni que haga superfluas las consideraciones críticas que del mismo han hecho algunas lecturas crítico-feministas. Jauch insiste en sostener 
que «Para Kant, en cualquier caso, las Observaciones no significan la última palabra sobre la cuestión de la diferencia sexual, sino que más bien suponen la ocasión para una profundización filosófica en esta temática" (Jauch, 1988, 114); pero, dicho esto, la propia Jauch tiene que reconocer que, incluso años después, «Kant sigue sustrayéndose a la cuestión política central del movimiento de mujeres: ¿Qué pasa con los derechos políticos?» (Jauch, 1988, 202).

\section{Kant y el pensamiento de la diferencia sexual}

Cuando Kant extrae en las Observaciones las consecuencias de su esencialismo sobre la diferencia sexual, su discurso pasa a marcar cómo debe ser una pedagogía femenina, totalmente diferenciada de la del varón y orientada a lo sensible, es decir, lo más alejada posible de todo lo que pueda ser abstracto saber intelectual. La tesis que late en estas afirmaciones no es otra que la de conservar los caracteres femeninos, de tal manera que se preserve la diferencia entre lo que en las Observaciones se viene a llamar el «sexo bello» y el «sexo sublime». El «sexo bello» ha de estar preparado para ejercer su «bella virtud» en los conflictos de la relación intra-familiar "por razón del conocimiento intrínseco y de la comprensión que tiene de las constelaciones inherentes a la razón de la necesidad» (Jauch, 1988, 96). Y, para ello, no hay necesidad alguna de equiparación entre los sexos, pues la caracterología femenina hace prescindible toda necesidad de saber más allá de su atención al ámbito privado y doméstico. Así escribe Kant sin ningún reparo que «el contenido de la gran sabiduría de la mujer es ante todo la persona y, entre las personas, el hombre» (Kant, 1977 a, 853).

Escindidos los sexos por razón de naturaleza, Kant se ve obligado ahora a dar cuenta de cómo es posible la unidad de la diversidad, manteniendo las diferencias. La solución de unidad de lo diverso entre los sexos pasa por el matrimonio como lugar de la complementariedad, que no significa indiferenciación para el Kant de las Observaciones: «En la vida conyugal, la pareja unida debe expresar también una única persona moral, animada y regida por el entendimiento del hombre y por el gusto de la mujer» (Kant, 1977a, 867). Esta diferenciación de funciones en razón del sexo hace que, en contraste con la reciprocidad entre los sexos en el matrimonio de carácter estrictamente jurídico, no haya en Kant una igualdad correspondiente en lo que se refiere sus relaciones domésticas y privadas (Kuster, 2011). 
De nuevo Ursula Pia Jauch relee esta tesis kantiana en clave claramente positiva, cuando afirma: «La reducida capacidad intelectualmente validable de la mujer se corresponde con su capacidad pasiva para elevar el nivel ético de los hombres en el sentido de la virtud verdadera» (Jauch, 1988, 93). La invocación a la diferencia sexual que hay que preservar del Kant de las Observaciones viene a complementarse años después con las aportaciones en torno al tema que aparecen en la Anthropologie (Antropología desde el punto de vista pragmático).

La propia Ursula Pia Jauch piensa que el verdadero lugar donde se juegan la diferencia y la unidad de los sexos en Kant es la Antropología de 1784. Al menos piensa que aquí se juegan en tanto que relaciones entre los sexos y, por lo mismo, en tanto que perspectiva pragmática que no puede ceder su interpretación a un más abstracto lugar de conocimiento; dice Jauch:

En tanto que la diferencia sólo es observable en la esfera de la empiria, de la experiencia social que pertenece al terreno de lo a posteriori, le toca a la Antropología la difícil tarea de pensar las diferencias antropológicas entre las personas sexuales en la unidad de la persona racional (Jauch, 1988, 191).

Frente a esta lectura más aséptica de Jauch señalemos aquí que, al ser precisamente el terreno pragmático el que se transita, cabe suponer que las consecuencias prácticas de la intelección kantiana de la unidad entre los sexos tendrán además un calado mucho menos inocente, que las que pudieran suponerse para un uso teórico de la razón.

Cuando volvemos al terreno de las relaciones entre los sexos encontramos la intelección del matrimonio moderno-burgués como terreno donde se da la unidad, como conquista civilizatoria, que beneficia en particular a la parte más frágil de esa unidad, esto es a las mujeres. Piensa Kant en el matrimonio y, de hecho, en el matrimonio monógamo: «En el estado burgués la mujer no se entrega sin matrimonio al disfrute del hombre y, de hecho, sin el matrimonio monógamo» (Kant, 1977b, 650). Hay que recordar que también en Rousseau el matrimonio aparece como terreno donde la complementariedad entre los sexos viene a realizarse, si bien se mantiene aquí la irreductibilidad de un sexo a otro en virtud de una expresa independencia masculina que hace al hombre más libre que a la mujer. Rousseau lo manifiesta así en su Emilio o de la educación: 
La mujer y el hombre están formados el uno para el otro, pero no es igual la dependencia; los hombres dependen de las mujeres por sus deseos y las mujeres dependen de los hombres por sus deseos y sus necesidades. Nosotros si ellas subsistiríamos mejor que ellas sin nosotros (Rousseau, 1979, 508-9).

Tanto en Rousseau, como en Kant parece claro que la libertad femenina sólo puede darse en su máximo grado por su condición de complemento del hombre y en la unidad que deviene por tal complementariedad. Hacerse «la mujer libre por el matrimonio» (Kant, 1977b, 656) puede leerse, por tanto, en el sentido de venir a ser partícipe subsidiariamente de la auténtica libertad que es siempre masculina.

Al tratar de la relación entre los sexos nos movemos, por tanto, en el terreno de la antropología que, en tanto que terreno de lo social, tiene que tomar en cuenta las variables empíricas que entran en juego. Pero cabe decir que hay algo de metafísico en la idea de la reunión de los sexos en una sola persona moral como diversidad que convoca su propia unidad: se establece aquí una diferencia sexual que viene a convocar su propia unidad, no por motivos meramente empíricos o sociales, sino por aquellos que responden a un orden de necesidad teleológica.

Aun cuando Adorno en su Dialéctica Negativa se halle lejos de remitir sus palabras al terreno de las relaciones entre los sexos, cabe aplicarlas en tal dirección cuando afirma: «Kant expresa, falible y deformadamente, lo que con razón habría que exigir socialmente» (Adorno, 1975, 273); y de ello concluye que «reducir la deformación a procesos metafísicos en vez de a circunstancias de la producción material, equivale de hecho a producir ideología» (Adorno, 1975,282). Es obvio que Adorno critica aquí el discurso de la ideología idealista, y que no se refiere obviamente a esa deformación del pensamiento que produce una ideología patriarcal. Pero, si de la mano de la crítica feminista llevamos esta reflexión de Adorno más allá de su propio objetivo, podemos hablar también de la producción de este tipo de ideología. Porque tal ideología también hace abstracción de las condiciones de producción material de la exclusión de las mujeres de la ciudadanía y de su situación de desigualdad de facto, haciendo pasar «deformadamente» por orden natural mismo lo que no es sino producto de relaciones socio-históricas. Y esta ideología tiene unos efectos directos en la 
práctica y en la política, como podemos ejemplarizarlo en el caso del ciudadano Emilio de Rousseau.

Recordemos brevemente que en el capítulo V de su Emilio o de la educación Rousseau se propone diseñar el prototipo de compañera que a éste convenga, $y$ habla de cómo debe ser educada Sofía. Ahora el contractualismo rousseauniano, que explica la génesis de toda desigualdad como fruto de una construcción social, viene a explicar la dependencia femenina como algo natural. De este modo, Rousseau dibuja la imagen de la mujer doméstica (Armstrong, 1991) y viene a consolidar las aspiraciones de la burguesía emergente en el orden de la vida privada, así como en la normatividad que establece qué es lo que realmente cabe entender por feminidad. Con ello se legitima el discurso de la exclusión de la mujer de la vida pública y de los parámetros de ciudadanía que caracterizan a la modernidad, de la que somos herederos. Tal como lo resume Celia Amorós: "Como el dominio político no está abierto a Sofía son evidentes los límites de su igualitarismo (del de Rousseau): la igualdad es un principio para el gobierno entre los hombres, no entre hombres y mujeres» (Amorós, 1997, 155).

Hay que volver a recordar que, en muchos aspectos de su filosofía, Kant era rousseauniano. También cabe afirmarlo para su conceptualización de los sexos y de la necesidad de que las mujeres preservaran sus caracteres específicos. En este sentido, Jauch achaca a Kant la misma exclusión de las mujeres del ámbito público presente en Rousseau y apunta además a la idealización kantiana del matrimonio, que le lleva a celebrar la monogamia como conquista civilizatoria. En este sentido Ursula Pia Jauch escribe:

La praxis del derecho conyugal burgués según Kant sigue el camino de unas relaciones cada vez menos susceptibles de ser entendidas como el intercambio entre dos sujetos, donde la pregunta por la relación de lo humano con lo otro está subordinado hace tiempo al derecho positivo natural. El matrimonio no es ese lugar interior, tomado de la utopía, del ser igualitario de dos personas de distinto sexo, como Kant lo expone en algunos lugares, sino que se ha convertido, con la usurpación por medio del derecho positivo, en un instrumento económico de la transmisión de nombres, bienes y capital (Jauch, 1988, 180).

Pero la celebración de la monogamia y la crítica de la poligamia no es privativa de este filósofo y estaba presente en la propia tradición del siglo XVIII 
en pensadores anteriores a Kant. Es el caso, por ejemplo, de la Cartas persas, en las que Montesquieu hace que sus personajes, Ubsek y Rhade establezcan un diálogo que, más allá de las consideraciones político-filosóficas, viene a centrarse en el harén oriental y a criticar ese universo polígamo en tanto negativo para las mujeres.

A la hora de dar cuenta de cómo es posible la unidad de la diversidad hay que volverse, tanto en Kant como en general en los contractualistas, a la noción de individuo. Porque es el individuo, en tanto que sujeto del pensamiento burgués, el referente para la nueva noción de ciudadanía. Ese individuo que, según Adorno, Kant se atreve a pensar como "la espontaneidad del sujeto como cosa en sí misma» (Adorno, 1975, 286), es un sujeto político en Kant sólo porque es un sujeto moral de manera imperativa. Y Adorno critica esta posición de Kant como ideología idealista que no entiende al individuo preeminentemente como ente social y lo abstrae del campo de las relaciones materiales de su producción. Dando una vuelta de tuerca a esta crítica de Adorno, cabe decir que también la crítica feminista vendría a impugnar la ideología que, como en el caso del propio Kant, pretende hablar de un sujeto humano universal y autónomo, pero que deja fuera de ese discurso a todo el colectivo femenino y sus condiciones materiales de opresión, con lo que su vocación de universalidad se ve auto-impugnada.

Sin embargo, algunos ecos de la filosofía kantiana entre los sexos parecen resonar en un pensamiento de la diferencia sexual que, desde el feminismo contemporáneo, ha reclamado la dualidad de géneros y la necesidad de preservar la diferencia femenina. Es el caso de la pensadora francesa Luce Irigaray, figura fundacional de ese pensamiento de la diferencia sexual en las últimas décadas del siglo pasado. No entraremos aquí a considerar las posiciones teóricas de esta autora, pero sí queremos recordar brevemente algunos lugares textuales, especialmente en dos de sus primeras obras, donde tales ecos se hacen, a nuestro juicio, más patentes. Así, por ejemplo, Irigaray declara que

Lo natural es por lo menos dos: masculino y femenino. Todas las especulaciones sobre la superación de lo natural en lo universal olvidan que la naturaleza no es una (...). Así, también para estas dos partes del género humano, que son el hombre y la mujer. Sólo abusivamente son reducidas a uno. La razón muestra, en esta reducción, su impotencia o su inmadurez(...) El género humano, pues, no habría alcanzado la edad de la razón (Irigaray, 1994, 57-8). 
Este hincapié en la dualidad sexual puede recordar aquellos pasajes kantianos, en particular de las Observaciones sobre el sentimiento de lo bello y lo sublime de 1764 , donde se predica la necesidad de una pedagogía específica para las mujeres. Tal pedagogía tiene como objetivo impedir que la caracterología esencial de ambos sexos venga a confundirse, convirtiendo en identidad lo que ha de ser fruto de la diversidad natural. Como Kant, en concreto en la Antropología desde el punto de vista pragmático de 1798, Irigaray reclama la relevancia de pensar la condición femenina, subrayando que "La diferencia sexual representa una de las cuestiones o la cuestión que debe pensarse en nuestra época. Cada época- según Heidegger- debe pensar una cosa. Solamente una. Probablemente la diferencia sexual sea la que corresponde a nuestro tiempo» (Irigaray, 2010, 35). Y, además, Irigaray entiende que no pensar la diferencia sexual implica moverse en el reduccionismo de un sexo a otro por el que, afirma, la razón no habría llegado a su plena madurez.

A pesar de su crítica al proyecto ilustrado de igualdad, algunas tesis de Irigaray resultan ser paradójicamente cercanas a la filosofía de los sexos de un filósofo tan ilustrado como es Kant. Porque esta filósofa se remite a una esencia femenina, oculta en la historia del devenir simbólico masculino y perdida en sus márgenes, que ha de preservar su diferencia esencial. De modo que también en Irigaray la diferencia sexual deviene en diferencia esencial (Posada Kubissa, 2005). Hay que decir, no obstante, que en Irigaray el lugar de la diferencia femenina viene a situarse en el placer y en la propia morfología, en lo que ha sido impensado: así, para ella

el cuerpo femenino servirá, pues, de núcleo para un nuevo discurso que se oponga al discurso patriarcal y, en conexión con él, situará al placer (la jouissance) de la mujer, que es la mayor amenaza para el discurso masculino, puesto que representa su irreductible "exterioridad" (Oliva Portolés, 2009, 234).

Por tanto, en Irigaray «se trata de la afirmación de la diferencia, de una nueva "erótica", que no se puede conceptuar porque todo concepto está ligado a la Ley del Padre o al significante fálico» (Femenías, 2000, 172). De modo que la diferencia femenina encuentra su fundamento en la morfología genital y en el placer, concepción esta que es deudora del discurso lacaniano en el que Irigaray se ha formado. Sin embargo, y a pesar de esta radical distancia del discurso 
patriarcal, el resultado es que se cultiva aquí la idea de una esencia propia y diferenciada del ser femenino, una idea que no parece tan alejada paradójicamente del esencialismo propio de discursos anteriores que, como el del propio Kant, también suscribirían tal esencialismo.

Cuando Irigaray plantea hacer una crítica severa a la lógica binaria propia de todo discurso falo-logo-céntrico, de todo discurso "ligado a la Ley del Padre", se refiere explícitamente a Kant. Y señala la necesidad de transformar su pensamiento, y todo el pensamiento precedente de nuestra tradición desde la asunción de la diferencia sexual. Así declara que

para que la obra de la diferencia sexual pueda hacerse realidad, es necesario que se produzca de hecho un vuelco del pensamiento y de la ética. Todo en la relación entre sujeto y discurso, sujeto y mundo, sujeto y lo cósmico, entre micro y macrocosmos tiene que ser significado de nuevo. Todo, y en primer lugar el hecho de que el sujeto siempre ha sido determinado de modo masculino, incluso cuando se ha querido presentar como universal o neutral (Irigaray, 2010, 36)

Sin embargo, la propuesta de la pensadora francesa no llega a ser más que eso y, en realidad, la transformación sugerida no viene a concretarse en ninguna parte de esta Ética de la diferencia sexual. Así lo ha criticado, por ejemplo, la filósofa alemana Alexandra Busch, cuando sostiene con cierta irritación que

Si atendemos más detenidamente al texto (de Irigaray) - y a ello nos obliga el mismo, que resulta incomprensible en un primer vistazo-, reconoceremos en él propuestas reformistas, en el mejor de los casos. Y las supuestamente nuevas concepciones y relaciones son, como mucho, variantes descuidadas hasta ahora de pensamientos pre-existentes (Busch, 1989, 169). 


\section{Dos breves conclusiones}

Por resumir aquí la tesis central de Irigaray, la diferencia sexual, entendida «como natural y universal» (Irigaray, 1994, 67) pasa a constituirse en aquello que no precisa de fundamentación y que, como en el caso de Rousseau, viene a legitimarse en el paradigma de naturaleza: «En la propia naturaleza, ésta encuentra su límite, que ya se halla en la generación pero también, horizontalmente, en la diferencia entre femenino y masculino» (Irigaray, 1994, 66). Si esto es así, se precisará según esta autora de «una cultura de lo sexual, aún inexistente», y que refleje «lo que las mujeres necesitan, a saber: una cultura adaptada a su naturaleza» (Irigaray, 1994,72). Esta propuesta viene a coincidir, como venimos viendo, con la concepción kantiana de una educación especial para el ser femenino, así como con la comprensión de la diferencia sexual como diferencia esencial. De modo que, como se ha querido sugerir aquí, una primera conclusión será que este dualismo antropológico, que Luce Irigaray defiende como irreductible en el discurso del denominado pensamiento de la diferencia sexual de los años $80 \mathrm{y}$ 90 del siglo XX, aun sin reconocer sus herencias, nos remite a las observaciones y a la filosofía kantianas sobre los sexos, y permite establecer entre ambos pensamientos, alejados cronológica e ideológicamente, más de una afinidad.

Una segunda conclusión nos podría conducir a que, si tratamos de entender la filosofía de los sexos de Kant podemos pensar, como lo piensa Jauch, que en ella hay un proyecto de perfectibilidad del ser femenino, porque este ser, si bien no ha llegado aún al desarrollo moral del ser masculino, está en disposición de hacerlo (Jauch, 1988). Hay que decir, sin embargo, que se hace difícil coincidir con el optimismo hermenéutico de Jauch, si tenemos a la vista las tesis kantianas sobre una caracteriología femenina que, entre otras cosas, no ha sido creada para la vida pública, que sólo se ha de interesar por los asuntos domésticos y que, sobre todo, es bueno que sea y siga siendo así, porque de este modo «los hombres pueden reponerse de sus problemas de la vida pública» (Stopzik,1980, 128). Más allá de cualquier otra consideración, lo cierto es que la filosofía de los sexos de Kant compone un pasaje poco transitado de su pensamiento. Recorrerlo y tratar de interpretarlo es una tarea que ha de interesar en particular a la crítica feminista, a ese feminismo filosófico desde el que nos hemos querido mover aquí. 


\section{Referencias bibliográficas}

Adorno, T. (1975). Dialéctica Negativa. Madrid: Taurus Humanidades

Amorós, C. (directora) (2000): Feminismo y Filosofía. Madrid: editorial Síntesis

Amorós, C. (1997): Tiempo de feminismo. Sobre feminismo, proyecto ilustrado y postmodernidad. Madrid: Cátedra

Armstrong, N. (1991). Deseo y ficción doméstica. Madrid: Ed. Cátedra

Сово, R. (1996). Fundamentos del patriarcado moderno. Jean-Jacques Rousseau. Madrid: Cátedra

Beaujean, M.(1969). «Das Bild des Frauenzimmers in Roman des 18. Jahrhundert», Wolfenbüttel: Wolfenbüttlerer Studien zur Aufklärung, III, 2-24

Bennet-vahle, H.(1991). «Die Differenz ist aussgesclossen. Aktuelle Überlegungen zur Geschlechtsanthropologie Kants». En Konnertz, Ursula (ed.), Grenzen del Moral. Ansätze feministischer Vernunftkritik. Tubinga: Edition Diskord, 31-57

Bovenschen, S. (1979). Die imaginierte Weiblichkeit. Exemplarische Untersuchungen zur kulturgeschichtlichen und literarischen Präsentationsformen des Weiblichen. Frankfurt: Suhrkamp Verlag

Busch, A.(1989). «Die metaphorische Schleier des ewig Weiblichen. Zu Luce Irigaray Ethik der sexuellen Differenz ». En: Grossman,R. y Schmere, C. (eds.), Feministischer Kompass, patriarchales Gepäck. Frankfurt: Suhrkamp, 152-173

Buytendijk, F.(1953). Die Frau. Natur-Erscheinung-Dasein. Colonia: J. P. Bachem Verlag

Duden, B. (1977). «Das schöne Eigentum. Zur Herausbildung bürgerlichen Frauenbildes an der Wende vom 18. zum 19. Jahrhundert». Berlin: Kursbuch 47, 125-142

Femenías, M. L. (2000). Sobre sujeto y género. Lecturas feministas desde Beauvoir a Butler. Buenos Aires: Ctálogos

Flandrin, J.-L.(1977). Orígenes de la familia burguesa. Barcelona: Grijalbo

HaY, C. (2013). Kantianism, Liberalism, and Feminism. Resisting Opression. New York: Palgrave Macmillan.

Irigaray, L. (1994). Amo a ti . Barcelona : Icaria

Irigaray, L. (2010). Ética de la diferencia sexual. Castellón: Ellago Ediciones

JaUCH, U. P. (1995). Filosofía de damas y moral masculina. Madrid : Alianza Universidad 
JaUCH, U. P. (1988). Immanuel Kant zur Geschlechterdifferenz. AufklärischeVorurteilskritik und bürgerlische Geschlechtsvormundschaft. Viena: Passagen Verlag

Kant, I.(1977 a). Beobachtungen über das Gefühl des Schönen und Erhabenen. Weischedel (ed.), Werkausgabe Immanuel Kant, Werke in 12 Bänden, II. Frankfurt: Suhrkamp Verlag, 825-868

KanT, I.(1977 b). Anthropologie in pragmatischer Hinsicht. Weischedel (ed.), Werkausgabe Immanuel Kant, Werke in 12 Bänden, XII, 2. Frankfurt: Suhrkamp Verlag, 399-685

Kant, I. (1997 c). Die Metaphysik der Sitten. Weischedel (ed), Werkausgabe Immanuel Kant, Werke in 12 Bänden, VIII. Frankfurt: Suhrkamp Verlag, 308-634

Kersting, W: (2012). «Inmanuel Kant: vom ästhetischen Gegenverhältnis der Geschlechter zum rechtlichen Besitzverhältnis in der Ehe», En: Marion Heinz y Sabine Doyé (eds.), Geschlechterordnung und Staat. Legitimationsfiguren der politische Philosophie (1600-1850), Berlin: Akademie Verlag GmbH, 163-180.

Kuster, F.(2011). «Verdinglichung und Menschenwürde. Kants Eherecht und das Recht der häuslichen Gemeinschaft». Kant-Studien, volumen 102, número 3, 335349

Moser, S. (2001), «Kant über die "natürliche" Unterlegenheit der Frau. Eine feministische Kritik». Sofia: En Institute for Philosophical Research Bulgarian- Academy of Sciences, Philosophy between Two Centuries, 252 - 258.

Nolte, U.(1963). «Frauenbild und Frauenbildung in der Geschlechterphilosophie Kants», Zeitschrift für Philosophie, año 9º, 346-362

Oliva portolés, A. (2009). La pregunta por el sujeto en la teoría feminista. El debate filosófico actual. Madrid: Editorial Complutense- Instituto de Investigaciones Feministas UCM

Pateman, C.(1995). El contrato sexual. Barcelona: Anthropos

Posada Kubissa, L. (2008). Razón y conocimiento en Kant. Madrid: Biblioteca Nueva

Posada Kubissa, L. (2005). « La diferencia sexual como diferencia esencial: sobre Luce Irigaray». En Amorós, Celia y de Miguel, Ana (eds.), Teoría feminista: de la Ilustración a la globalización. Madrid: Minerva Ediciones, tomo 2, 253-288

Rousseau, J.-J. (1979). Emilio o de la educación. Barcelona, Editorial Bruguera, 1979

SteinbrüGge, L. (1989). "Vernunftkritik und Weiblichkeit in der französischen Aufklärung». En Deuber-Mankowsky, Astrid; Ramming, Ulrike; Tielsch, Elfriede Walesca (eds.), 1789/1989. Die Revolution hat nicht stattgefunden. Tubinga: Edition Diskord, 65-79

Sторzук, А. Sторzук, (1980). Was Philosophen über Frauen denken. Munich: Mathes und Geitz Verlag 
Aceptado: 16/11/2014

Revisado: 26/01/2015

Este trabajo se encuentra bajo una licencia de Creative Commons ReconocimientoNoComercial-SinObraDerivada 4.0

\section{(c)}


